\title{
El libro en la corte. Lecturas femeninas y sus espacios palaciegos en la Baja Edad Media
}

Los espacios destinados a la cultura escrita en los ámbitos palaciegos bajomedievales, tanto nobiliares como cortesanos, apenas han recibido atención específica por parte de la historiografía que ha priorizado el estudio del contenido sobre el del continente. Esta carencia es aún más llamativa al referirnos a los lugares destinados a dichos propósitos vinculados a las mujeres.

\section{La consideración de la mujer}

En la Baja Edad Media el papel de la mujer en la residencia palaciega estuvo determinado por una serie de valores y atribuciones que establecieron las acciones y conductas que las mujeres debían llevar a cabo, y que estaban fuertemente influidos por los presupuestos de género impuestos por los grupos de poder y la Iglesia. ${ }^{1}$ La mujer administraba la residencia, tanto en lo referente a la economía, como a los empleados, ${ }^{2}$ e incluso actuaba como sustituta de su consorte a la hora de ejercer el poder y control de sus dominios en caso de ausencia del mismo. ${ }^{3}$

Entre las atribuciones dadas a la mujer en este periodo, cabe destacar su implicación en la educación y su faceta piadosa. La primera educación de los hijos corría a cargo de la madre, pero su influencia podía ser mucho mayor, puesto que era la mujer la encargada de elegir a los tutores de su descendencia, así como influir en las elecciones educacionales con peso para el futuro. ${ }^{4}$ Esta vertiente instructiva ejercida por la mujer en el ámbito doméstico queda reflejada en la representación iconográfica de la Santa Ana Triple, como puede ser la custodiada en

1 Sobre la situación de la mujer noble en la Baja Edad Media vid. I. Beceiro Pita, La mujer noble en la Baja Edad Media castellana, in Y. R. Fonquerne - A. Esteban (coord.), La condición de la mujer en la Edad Media, Madrid, Casa Velázquez, UCM, 1986, pp. 287-313.

2 I. Beceiro Pita, La mujer noble en la Baja Edad Media castellana, cit., p. 293.

3 I. Beceiro Pita, Modelos de conducta y programas educativos para la aristocracia femenina (siglos XII - XV), in M. T. López Beltrán (coord.), De la Edad Media a la Moderna: Mujeres, educación y familia en el ámbito rural y urbano, Málaga, Universidad de Málaga, 1999, pp. $37-72$ (p. 41).

4 Ibid., p. 69.

Cristina Pérez Pérez, Universidad Complutense de Madrid

Ә Open Access. (c) 2018 Cristina Pérez Pérez, published by De Gruyter. (cc) BY-Nc-ND This work is licensed under the Creative Commons Attribution-NonCommercial-NoDerivatives 4.0 License. https://doi.org/10.1515/9783110596755-041 
Museo Diocesano de Palencia, la Santa Ana y la Virgen niña del Museo Nacional de Arte de Cataluña o la representación de Blanca de Castilla observando las clases de su hijo, del Libro de Horas de Juana de Navarra, datado hacia 1336-1340 (BnF, ms. nouv.acq. lat. 3145, f. $85 \mathrm{v}$ ), en las que se enfatizan los conceptos de aprendizaje y docencia asociados a la mujer, ya sea en su cometido de transmisión de valores morales o como supervisora de la educación de sus hijos. ${ }^{5}$

Por lo que respecta a la faceta piadosa, esta marcó la identidad femenina de manera determinante, ya que, según numerosos tratados de la época, era una virtud que toda dama debía poseer. ${ }^{6} \mathrm{El}$ desarrollo de dicha virtud estuvo íntimamente vinculado con la lectura de textos devocionales, vehículo imprescindible para acercarse a la divinidad. ${ }^{7}$

Son numerosas las representaciones iconográficas en las que este aspecto queda reflejado, siendo una de las de mayor relevancia la Anunciación, que insiste en la importancia de la palabra en el cristianismo. ${ }^{8}$ La Virgen aparece orando sobre un reclinatorio que en numerosas ocasiones hace las veces de armario o pupitre, o bien en actitud lectora, revelando comúnmente elementos vinculados a la cultura libraria. Un buen ejemplo de ello es la Anunciación del Tríptico Merode realizado por el taller de Robert Campin (1427-1432), conservada en el Metropolitan Museum of Art de Nueva York, en la que la Virgen aparece leyendo en un espacio doméstico, junto a una mesa en la que reposa un manuscrito y un pliego con alguna oración, así como una camisa en la guarda el volumen.

5 I. Beceiro Pita, Modelos de conducta, p. 60.

6 Sirvan de ejemplo: De claris mulieribus de Boccaccio, la obra de Fray Hernando de Talavera, De como se ha de ocupar una señora cada dia para pasarle con prouecho, el Livre des trois Vertus a l'enseignement des Dames et Daimoiselles, escrito por Christine de Pizan, el Libro de las virtuosas é claras mujeres el qual fizo é compuso el condestable don Álvaro de Luna maestre de la orden de Santiago o el Tratado en defensa de las virtuosas mujeres de Diego de Valera, entre otros muchos. Esta faceta piadosa se vio reflejada en acciones como la fundación de templos y monasterios, las donaciones, el tomar a cargo a pobres y huérfanos, la prudencia o la capacidad de buen consejo al gobernante, convirtiéndose un elemento indispensable para las damas. Vid. al respecto J. Yarza Luaces, La nobleza ante el rey. Los grandes linajes castellanos y el arte del siglo XV, Madrid, Ediciones el Viso, 2003, p. 197; y M. Morrás Ruiz-Falcó, Ser santa y mujer (Península Ibérica, siglos XV-XVII), in “Medievalia”, 18 (2), 2015, pp. 9-24 (p. 11).

7 En este momento surge la Devotio moderna, una nueva forma de religiosidad que promovía la práctica religiosa individual, en la que tuvieron gran relevancia los Libros de Horas y la lectura silenciosa, tal y como se explicará infra.

8 La importancia dada a la palabra divina se refleja en numerosas representaciones en las que se alude a la escritura y la lectura, insistiendo en modelos devocionales y, al mismo tiempo, sirviendo de reflejo de la realidad cotidiana de la época. Vid. I. Beceiro Pita, Libros, lectores y bibliotecas en la España medieval, Murcia, Nausícaa, 2006, p. 490. 
Por otro lado, la representación de modelos de virtud mediante santas que responden a la imagen de sabiduría y a los ideales que debía poseer una mujer en el periodo bajomedieval nos proporciona otro modelo iconográfico de gran valor en el estudio de la cultura libraria. ${ }^{9}$ La aparición de Santa Catalina de Alejandría o Santa Bárbara como principales exponentes de este modelo, ya sea como acompañantes de otro tema o bien como protagonistas de la obra artística, supone una aproximación a los usos del libro en ámbito femenino de excepcional valor informativo. ${ }^{10}$ Estas santas son habitualmente representadas en actitud lectora, siguiendo las pautas que veíamos previamente en la Anunciación, o sosteniendo un volumen en sus manos, y en numerosas ocasiones se encuentran en ámbitos domésticos que introducen visualmente en la realidad de la época, tal y como ocurre en la Santa Bárbara del Museo del Prado, realizada por Robert Campin.

\section{El papel del libro en la vida de la mujer}

Si el libro desempeñó un papel imprescindible en el desarrollo del registro docente y piadoso de las mujeres en la baja Edad Media, también lo hizo en la construcción de la identidad de la mujer noble en su faceta mundana. ${ }^{11}$ El libro se convierte en atributo distintivo de la mujer, siendo un integrante fundamental en

\footnotetext{
9 Esta representación se interpreta como la contraposición del modelo masculino de la escritura, los Evangelistas, los Padres de la Iglesia u otros santos eruditos, I. Beceiro Pita, Modelos de conducta, cit,. p. 22.

10 J. Yarza Luaces, La santa que lee, in T. Sauret Guerrero, A. Quiles Faz (coord.), Luchas de género en la Historia a través de la imagen, Málaga, CEDMA, 2001, pp. 421-465; M. Morrás RuizFalcó, Ser santa y mujer, cit.

11 I. Beceiro Pita, Los espacios del libro en Castilla y Aragón a fines del Medievo, in "Litterae. Cuadernos sobre Cultura Escrita”, I, 2001, pp. 119-136 (p. 119). La gran importancia del libro en la vida femenina de la Baja Edad Media propició su presencia en la escultura funeraria. Numerosos sepulcros presentan damas yacentes sosteniendo un libro abierto entre sus manos, mostrando a su poseedora como una mujer culta, erudita y, ante todo, devota. Una de las representaciones más destacadas de este modelo iconográfico es el Sepulcro de Juan II e Isabel de Portugal, obra de Gil de Siloé y situado en la Cartuja de Miraflores en Burgos. Vid. al respecto J. Yarza Luaces, Los sepulcros reales de la Carttuja de Miraflores, in "Cuadernos de Restauración de Iberdrola", XIII: La Cartuja de Miraflores I. Los sepulcros, 2007, pp. 15-74 (p. 26); J.P. Cruz Cabrera, La escultura castellana en tiempos de Doña Isabel la Católica: de la tradición medieval a la modernidad humanista, in J. M. Martín García (coord.), Modernidad y cultura artística en tiempos de los Reyes Católicos, Granada, Universidad de Granada, 2014, pp. 89-114 (p. 106); M.J. Gómez Bárcena, Escultura gótica funeraria en Burgos Madrid, Diputación de Burgos, 1988, p. 213.
} 
el espacio femenino dentro del palacio, ${ }^{12}$ pues atienden a todos aquellos aspectos de relevancia en el desarrollo de la vida de las mujeres: intelectual, espiritual, docente o litúrgico. ${ }^{13}$

La insistencia en la religiosidad como virtud vinculada al género femenino propició que las bibliotecas de mujeres de la Baja Edad Media estuvieran dotadas en su mayor parte por volúmenes de carácter religioso, exaltándose la lectura de este tipo de obras para la sociedad femenina. ${ }^{14}$

Por otra parte, entre los siglos XII y XIII el concepto de sabiduría se vincula al poder, considerándose como elemento básico para su buen ejercicio. ${ }^{15} \mathrm{~A}$ pesar de que generalmente el poder se asocia a lo masculino, el papel de las damas de la aristocracia, - ya sean reinas, señoras o infantas- y su relación con el ejercicio de autoridad, propicia que este atributo sea asociado también a ellas, por lo que los saberes básicos del poder, tales como lectura, escritura, latín o los conocimientos sobre la administración y las relaciones internacionales, entre otros, son requeridos también en las mujeres nobles. Así, libros de carácter didáctico-moral, los espejos de príncipes, tratados sobre el buen gobierno, etc., formaron parte de sus bibliotecas como elementos útiles en el desempeño de sus labores gubernamentales.

12 La documentación reduce los espacios reservados a las mujeres en la residencia a la cámara, el estrado, retretes y oratorios. I. Beceiro Pita, "La mujer noble en la Baja Edad Media castellana”, in Y. R. Fonquerne - A. Esteban (coords.), La condición de la mujer en la Edad Media, Madrid, Casa Velázquez, UCM, 1986, p. 307.

13 P. M. Cátedra - A. Rojo, Bibliotecas y lecturas de mujeres. Siglo XVI, Salamanca, Instituto del Libro y de la Lectura, 2004, p. 183.

14 F. Dolbeau, Les usagers des bibliothèques, in A. Vernet (Dir.), Histoire des bibliothèques françaises. Les bibliothèques médiévales du VII ${ }^{0}$ siècle à 1530, Paris, Éditions du Cercle de la Librairie, 1989, pp. 395-413 (p. 398); G. Hasenohr, L'essor des bibliothèques privées aux XIVe et XVe siècles, in A. Vernet (dir.), Histoire des bibliothèques françaises, cit., pp. 215-263, p. 246; I. Beceiro Pita, La relación de las mujeres castellanas con la cultura escrita (siglo XIII - inicios del XVI), in A. Castillo Gómez, Libro y lectura en la Península Ibérica y América (siglos XIII a XVIII), Salamanca, Junta de Castilla y León, 2003, pp. 15-52 (p. 15). La información referente a los títulos es errónea en numerosas ocasiones, puesto que puede producirse un silencio documental sobre algunas obras, debido a que estas no fueran consideradas dignas de ser poseídas por determinados personajes (por ejemplo, novelas artúricas y sentimentales). También pueden faltar aquellas que se encuentran incompletas o desencuadernadas. Al mismo tiempo, se ha de tener en cuenta el uso colectivo de algunos libros por parte de la familia y su ausencia, por consiguiente, en los inventarios personales (Ibid., p. 17).

15 L. Fernández Fernández, Los espacios del conocimiento en palacio: de las arcas de libros a las bibliotecas cortesanas en el reino de Castilla, in "Anales de la Historia del Arte”, 23, $\mathrm{n}^{\circ}$ especial (II), 2013, pp. 107-125 (p. 108). C. Daniel, Le livre et l'exercice du pouvoir: culture livresque du monarque et symbole politique de la bibliothèque royale, in K. Ueltschi (ed.), L'Univers du livre médiéval. Substance, lettre, signe, Paris, Honoré Champion, 2014, pp. $73-92$ (p. 74). 
A finales de la Edad Media se aprecia un aumento en el número de bibliotecas particulares, ${ }^{16}$ hecho que afecta también a las colecciones femeninas, puesto que en este periodo se experimentó un acrecentamiento en la formación y erudición de las mujeres, ${ }^{17}$ que se reflejó en la definición de espacios específicos como los estudios o las bibliotecas, ${ }^{18}$ en los que las damas desarrollaron su pasión por el libro, siendo un excelente ejemplo de ello Christine de Pizan, cuyas obras tuvieron una gran relevancia en el periodo medieval, ${ }^{19} \mathrm{y}$ a la que podemos apreciar representada en uno de estos espacios en el folio 4r del Ms Harley 4431 de la British Library.

Por otro lado, en el mismo periodo es posible hallar ejemplos en los que el libro se encuentra disperso en los distintos ámbitos de la residencia, respondiendo a las diferentes necesidades o usos de la corte, tal y como se aprecia en el inventario de la condesa de Plasencia, Leonor de Pimentel, en el que los asientos mencionan libros en la cámara, la capilla y otros espacios. ${ }^{20}$ Incluso se puede

16 C. Faulhaber, Las bibliotecas españolas medievales, in J.M. Soto Rábanos (coord.), Pensamiento medieval hispano: homenaje a Horacio Santiago - Otero, Madrid, CSIC, 1998, pp. 785-800, p. 790; L. L. Fernández Fernández, Los espacios del conocimiento, cit., p. 116.

17 C. Segura Graiño, Mujeres educadas, mujeres instruidas, mujeres cultas, mujeres sabias, J.M. Soto Rábanos (coord.), Pensamiento medieval hispano, cit., pp. 901-911, p. 906.

18 Los primeros estudios surgen en Italia, siendo paradigmático el Studiolo de Cosme de Médicis. Estos espacios se desarrollan como estancia en la que los príncipes italianos guardaban sus colecciones librarias y en las que se dedicaban al estudio. La aparición de estas habitaciones destinadas a los libros y su consulta se extiende al resto de Europa, pudiendo encontrar referencias de su existencia en contextos tales como Borgoña o la Península Ibérica. Su uso no estaba restringido a los hombres, sino que algunas mujeres eruditas poseían estudios en los que se guardaban sus colecciones y se disfrutaba de las mismas. K. Staikos, The Great Libraries. Fron Antiquity to the Renaissance (3000 b.c. to a.d. 1600), Londres, Oak Knoll Press \& The British Library, 2000, p. 236; G. Lombardi - D. Nebbiai, Livres, lecteurs et bibliothèques de l'Itale médiévale (IXe - XVe siècles). Sources, textes et usages, Paris-Roma, CNRS Éditions, 2001; C. Rabel, L'estude d'un très noble seigneur garny a planté de plusieurs beaulx livres. L'iconographie des bibliothèques médiévales dans les manuscrits enluminés, in D. Bohler (ed.), Le goût du lecteur à la fin du Moyen Âge, Paris, Le Léopard d'or, pp. 245-289 (p. 266); D. Nebbiai, Le discours des livres. Bibliothèques et manuscrits en Europe, IXe - XVe siècles, Rennes, Université de Rennes, 2013, p. 196; L. Fernández Fernández, Los espacios del conocimiento, cit., p. 122; D. Plantey, Les bibliothèques des princesses de Navarre au XVe siècle: livres, objets, mobilier, décor, espaces et usages, Lyon, Presses de l’Enssib, Villeurbanne, 2016.

19 De la abundante bibliografía existente sobre la autora sirva a modo de introducción: L. DulacB. Ribémont, Une femme de lettres au Moyen Âge. Études autour de Christine de Pizan, Orleans, Paradigme, 1995; así como el artículo de Patrizia Caraffi publicado en el presente volumen.

20 A. Jiménez Moreno, Formación, uso y dispersión de una pequeña biblioteca nobiliaria del siglo XV: los libros de doña Leonor Pimentel, condesa de Plasencia, in N. Fernández Rodríguez - 
confirmar el desplazamiento de los libros junto con su poseedor en los frecuentes viajes que realizaban. ${ }^{21}$

\section{Los tipos de lectura como elementos condicionantes del espacio}

Una vez tenidos en cuenta estos dos elementos, el papel de la mujer en la corte y la importancia del libro en la vida de las damas, se han de distinguir las distintas modalidades de lectura que condicionan los espacios del libro: la lectura individual o silenciosa, y la lectura colectiva o en voz alta, coexistentes en el periodo bajomedieval. ${ }^{22}$

\subsection{Lectura colectiva o en voz alta}

La lectura colectiva o en voz alta era una práctica habitual en la difusión de los géneros narrativo en la Edad Media y en el entretenimiento de la corte. El ocio cortesano se nutría de diversas actividades, desde la ejercitación de las armas en tiempos de paz a través de la caza y torneos, a prácticas lúdicas como el juego de ajedrez y de dados. Una de las ocupaciones de deleite más relevantes fue la lectura de textos de carácter épico o histórico en el desarrollo de los banquetes como medio de asentar la memoria histórica y enaltecer el ánimo de los caballeros, tal y como se recoge en las Partidas de Alfonso X: "[leer durante la comida] estorias de los grandes fechos de armas que otros fizieran". ${ }^{23}$ Dado que las mujeres eran las principales destinatarias de las lecturas cortesanas, y en muchas ocasiones

M. Fernández Ferreiro (coord.), Literatura medieval y renacentista en España: líneas y pautas, Salamanca, USAL, SEMYR, 2012, pp. 655-663 (p. 657).

21 D. Quéruel, Du mécénat au plaisir de lire: l'exemple de quelques seigneurs bourguignons et en particulier de Luis de la Gruthuyse, in D. Bohler (ed.), "Le goût du lecteur”, cit., pp. 197-211 (p. 198). La presencia de los libros más preciados y otras posesiones personales de Isabel I de Castilla en Toro a su muerte demuestra esta práctica, puesto que estos eran transportados en cofres en los viajes regios. E. Ruiz García, Los libros de Isabel la Católica. Arqueología de un patrimonio escrito, Salamanca, Instituto de Historia del libro y de la lectura, 2004, p. 44; Acta de apertura e inventario de las arcas de Isabel la Católica, Archivo General de Simancas, $C M C, 1^{\text {a }}$ ép., leg. 81.

22 I. Beceiro Pita, La relación de las mujeres castellanas, cit., p. 28.

23 Texto de la Partida II, Título XXI, Ley 20, extraído de L. Fernández Fernández, Los espacios del conocimiento, cit., p. 116. 
las artífices de la acción lectora, ${ }^{24}$ la lectura colectiva se convirtió en uno de los principales medios de conocimiento de textos caballerescos entre la población femenina. ${ }^{25}$ Este hecho queda reflejado en un extracto del Caballero Zifar, en el que una dama lee ante los caballeros de la corte: "E la donzella lleuaua el libro de la estoria de don Yvan e començo a leer en el. E la donzella leye muy bien e muy apuestamente e muy ordenadamente". ${ }^{26}$

Además de las lecturas de gestas y hazañas caballerescas, los espacios comunes de la residencia palaciega también fueron escenario de otras actividades ociosas relacionadas con la lectura, como las representaciones teatrales o conmemorativas. ${ }^{27}$

En estrecha relación con el desarrollo del entretenimiento palaciego, la docencia fue otra de las facetas de mayor relevancia de la lectura colectiva o en voz alta. Se practicaba de manera similar a la lectio universitaria, es decir, mediante el comentario de textos ya leídos y la discusión sobre los mismos con el maestro, para el aprendizaje de textos históricos, escritos de carácter ético político, o filosófico - moral. ${ }^{28}$ La versión más común de la docencia en el ámbito palatino fue la formación de los vástagos de la familia o los descendientes de otras familias unidas mediante lazos de vasallaje. Como ya hemos mencionado previamente, el vínculo de las mujeres de la nobleza con la docencia de los descendientes fue una constante, quedando explicitado en gran cantidad de textos y referencias, tal y como se aprecia en la ilustración que representa una clase de lecturas en un Libro de Horas datado hacia 1445 y custodiado en la British Library de Londres (Ms. Harley 3828 f. 27v). ${ }^{29}$ Además de la labor docente en lo que respecta a la asimilación de contenidos profanos, el papel maternal en la formación

24 A. Jiménez Moreno, Formación, uso y dispersión, cit., p. 660. La lectura en voz alta fue una forma de sociabilidad, en la que se compartían lecturas institucionalizadas realizadas por uno o varios lectores. Los volúmenes destinados a este fin presentaban una estética lujosa: normalmente eran de gran formato, poseían ilustraciones y la escritura estaba adaptado a una lectura cómoda. Vid. al respecto C. Van Hoorebeeck, Du livre au lire. Lectures et lecteurs à l'épreuve des catégorisations sociales, in X. Hermand - E. Renard - C. Van Hoorebeeck (dir.), Lecteurs, lectures et groupes sociaux au Moyen Âge, Actes de la journée d'étude organisée par le Centre de Recherche Pratiques medievales de l'écrit de l'Université de Namur et le Dépt. des Manuscrits de la Bibliothèque royale de Belgique, Bruselas, Brepols, 2010, pp. 123-131 (p. 130); J. Coleman, Public Reading and the Reading in late medieval Engralnd and France, Cambridge - New York, Cambridge University Press, 1996; A. Manguel, Une histoire de la lecture, Arles, Actes Sud, 1998.

25 I. Beceiro Pita, Los espacios del libro en Castilla y Aragón, cit., p. 134.

26 Libro del caballero Zifar, ed. de Cristina González, Madrid, Gredos, 1998, p. 413.

27 I. Beceiro Pita, Modelos de conducta, cit., p. 66.

28 I. Beceiro Pita, Libros, lectores y bibliotecas en la España medieval, cit., p. 228.

29 L. Fernández Fernández, Los espacios del conocimiento, cit., p. 113. 
moral y religiosa fue igualmente relevante. ${ }^{30}$ Estas actividades eran llevadas a cabo en distintos ámbitos de la residencia palaciega, ya fuera en la colectividad de los salones o en la intimidad de las cámaras, como ilustran numerosas representaciones del periodo, como puede ser la escena en la que Christine de Pizan le entrega su obra a la reina Isabel de Baviera en su cámara, presente en el ms. Harley 4431, f. 3r de la British Library.

En lo que respecta a la lectura colectiva de carácter piadoso, se encontraba estrechamente vinculada a la liturgia y relacionada con el rezo, quedando su práctica reducida a oratorios o capillas. ${ }^{31}$ La insistencia de la piedad como requisito indispensable entre los atributos de una dama condiciona que sean las principales protagonistas de este tipo de actividad.

\subsection{Lectura individual o silenciosa}

Los siglos finales de la Edad Media fueron testigos del asentamiento de la lectura silenciosa o individual en la sociedad. ${ }^{32} \mathrm{El}$ auge de esta modalidad lectora está estrechamente vinculado con el desarrollo de la escolástica, ${ }^{33}$ ligada a la enseñanza universitaria, así como a otros factores como los cambios socioculturales que propiciaron un aumento de la bibliofilia en las élites o el crecimiento de la producción libraria. ${ }^{34}$ Se consideraba que la lectura silenciosa era la adecuada para una comprensión óptima de los textos, abordados desde un punto de vista íntimo y espiritual. ${ }^{35}$

30 Ibid., p. 69.

31 I. Beceiro Pita, La relación de las mujeres castellanas, cit., p. 29.

32 T. Van Hemelryck, Du libre lu au libre écrit. La lecture et la construction de l'identité auctoriale à la fin du Moyen Age, in Lecteurs, cit., pp. 185-194 (p. 185); L. Trunel, Histoire de la lecture, in A. Zali (dir.), La grande aventure du livre. De la tablette d'argile à la tablette numérique, Paris, BnF, 2013, pp. 154-174 (p. 158).

33 G. Cavallo - R. Chartier (dir.), Historia de la lectura en el mundo occidental, Madrid, Taurus, 2001, p. 184. El desarrollo de la lectura silenciosa propició cambios en la estructura de los textos, introduciéndose elementos que facilitaran al lector la comprensión textual, tales como los signos de puntuación entre otros (Ibid., p. 216).

34 H. Escolar Sobrino, Libros y bibliotecas en la Baja Edad Media, in J. I. Iglesia Duarte (coord.), La enseñanza en la Edad Media, X Semana de Estudios Medievales de Nájera, Nájera, Estudios Riojanos, 2000, pp. 269-302, p. 281; A. Antelo Iglesias, Las bibliotecas del otoño medieval. Con especial rederencia a las de Castilla en el siglo XV, in “Espacio, tiempo y forma”, III, $\mathrm{H}^{\mathrm{a}}$ Medieval, t. 4, 1991, pp. 285-350 (p. 292).

35 G. Cavallo - R. Chartier (dir.), Historia de la lectura, cit., p. 218. 
La lectura silenciosa estuvo vinculada fundamentalmente al estudio o al rezo. ${ }^{36}$ Tal y como informa la documentación, estas actividades eran llevadas a cabo comúnmente en las cámaras privadas o retretes, ${ }^{37}$ siendo al mismo tiempo el lugar de custodia de los volúmenes y de desarrollo de las lecturas. ${ }^{38}$

La práctica de la lectura de textos de carácter devocional estuvo estrechamente vinculada con la aparición de una nueva forma de religiosidad, la Devotio moderna, que promovía una espiritualidad centrada en la meditación, la observancia, la oración y la interiorización de los preceptos cristianos, favoreciendo la práctica de devociones privadas e individuales, que iban más allá de las actividades litúrgicas y se desarrollaban en la intimidad del domicilio. ${ }^{39}$

Los textos de mayor difusión vinculados a esta corriente son los Libros de Horas, cuya lectura se realizaba de manera apartada y silenciosa en espacios como los retretes y oratorios, ${ }^{40}$ tal y como refleja la bella representación del Libro de Horas de María de Borgoña (Viena, Biblioteca Nacional de Austria, Codex Vindobonensis 1857, f. $14 \mathrm{v}) .^{41} \mathrm{Y}$ como se indica en la obra compuesta por el confesor de Leonor de Pimentel, Juan López, en el Libro de las historias de nuestra Señora, en el que se hace referencia a la lectura individual y reflexiva necesaria a la hora de abordar el texto: "E mírelo vuestra alteza e léalo una vez siquiera vuestra devotíssima nobleza por deporte alegre e gozoso, fablando en el retrete

36 En la literatura se asocia también al sentimiento amoroso, pero es complicado saber el grado de realidad de estas prácticas (Ibid., p. 28).

37 El término "cámara" se refiere a la estancia con funciones de dormitorio, mientras que "retrete" hace alusión a una habitación destinada al retiro.

38 L. Fernández Fernández, Los espacios del conocimiento en palacio, cit., p. 114.

39 J. L. González García, Imágenes empáticas y diálogos pintados: arte y devoción en el reinado de Isabel la Católica, in M. J. Hueso Sandoval (coord.), Isabel la Católica. La magnificencia de un reinado. Quinto centenario de Isabel la Católica, 1504-2004, Salamanca, Sociedad Estatal de Conmemoraciones Culturales, 2004, pp. 99-114 (p. 99); J. Van Engen, Sisters and Brothers of the Common Life: The Devotio Moderna and the World of the Later Middle Ages, Philadelphia, University of Pennsylvania Press, 2008; W. Scheepsma, Medieval Religious Women in the Low Countries: The "Modern Devotion", the Canonesses of Windesheim, and Their Writings, D. F. Johnson (trasl.), Woodbrige, Boydell and Brewer, 2004; H. van Os, The Art of Devotion in the Late Middle Ages in Europe, Princeton, Princeton University Press, 1994.

40 I. Beceiro Pita, La relación de las mujeres castellanas, cit., p. 31.

41 La bibliografía sobre los Libros de Horas en la historiografía artística es muy extensa. Sirvan como títulos de referencia los ya clásicos estudios de L. M. J. Delaissé, The Importance of Books of Hours for the History of the Medieval Book, in U. E. McCracken - L. M. C. Randall - R. H. Randall, Jr. (eds.), Gatherings in Honor of Dorothy E. Miner, Baltimore, Walters Art Gallery, 1974, pp. 203-225.; R. S. Wieck, Time Sanctified: The Book of Hours in Medieval Life and Art, New York, 1988, y Painted Prayers: The Book of Hours in Medieval and Renaissance Art, New York, 1997. Sobre el Libro de Horas de María de Borgoña vid. E. Inglis, The Hours of Mary of Burgundy. Codex Vindobonensis 1857 Vienna, Österreichische Nationalbibliothek, Londres, Editions Harvey Miller, 1995. 
con la Madre del Gloriosísimo", ${ }^{42}$ así como en el escrito de Fray Hernando de Talavera dedicado a la condesa de Benavente:

Deueis luego rezar visperas y cumpletas de nuestra señora y las horas de defunctos si bastare la deuocion. Todo esto en vn retrete el mas quito de ruido que pudierdes auer: en elqual este vuestro oratorio tan limpio y tan compuesto que cada que enel entrardes vos de consolacion y conbide a devocion ${ }^{43}$

Como se ha mencionado, la lectura silenciosa se encuentra estrechamente ligada al estudio, y a la interiorización y comprensión profunda de los escritos. Este modo de acercamiento a los textos también fue practicado por las mujeres, en cuyas bibliotecas se encuentran presentes obras de índole diversa destinadas a ser abordadas de manera individual para su óptimo entendimiento. ${ }^{44}$ Los espacios que albergaron la práctica de estas lecturas individuales de las damas fueron las cámaras y retretes, así como los primitivos estudios que comienzan a aparecer a finales de la Edad Media ${ }^{45} \mathrm{y}$ que son el germen de las bibliotecas palaciegas.

\section{Conclusión}

Los espacios femeninos del libro en el ámbito palaciego en la Baja Edad Media se encuentran estrechamente vinculados a la consideración de la mujer en dicho periodo. En este sentido la importancia dada a la piedad como atributo inherente a las damas, propicia la presencia de textos religiosos en las bibliotecas femeninas de las postrimerías medievales y, al mismo tiempo, condiciona unos modos de lectura y unos espacios determinados: la lectura y rezo de obras devotas de manera colectiva realizada en la capilla; y, por otro lado, la lectura individual, conectada con la Devotio moderna y llevada a cabo en la intimidad del retrete, la cámara o el oratorio privado.

Además, la asociación del buen gobierno con la sabiduría determinó que las mujeres de la aristocracia, cercanas al poder, desarrollasen el estudio de textos que las acercara a la buena práctica de las actividades gubernamentales, ya sea

42 Recogido en A. Jiménez Moreno, Formación, uso y dispersión, cit., p. 659.

43 Fray Hernando de Talavera, De como se ha de ocupar una señora cada dia para pasarle con prouecho, Biblioteca de El Escorial, b IV. 26, fols. 25 y 26.

44 Los ejemplares destinados a dicho fin presentaban temáticas diversas, que van desde los textos de carácter moral y religioso, a obras científicas de carácter divulgativo o textos clásicos, así como volúmenes destinados a la relajación y el entretenimiento como la poesía o las novelas. I. Beceiro Pita, La relación de las mujeres castellanas, cit., p. 29.

45 D. Plantey, Les bibliothèques des princesses de Navarre, cit., p. 18. 
mediante el estudio individual desarrollado en las cámaras privadas y gabinetes, o bien mediante el aprendizaje dirigido por maestros $\mathrm{u}$ otras mujeres, puesto que estas estaban vinculadas a la primera educación, siendo las encargadas de la enseñanza de los vástagos, y desarrollándose estas actividades en diferentes espacios del ámbito residencial.

El entretenimiento cortesano estimuló la puesta en marcha de actividades en los espacios comunes de la residencia, en los que la mujer tenía una gran importancia, tales como la audición de textos y, al mismo tiempo, su lectura en voz alta o la participación en diferentes representaciones.

La relación de la mujer bajomedieval con la cultura libraria y el papel de las damas en el ámbito palaciego son dos elementos íntimamente relacionados al desarrollo de los usos del libro en la corte y, con ello, a la conformación de espacios específicos del libro en el palacio. 
